\title{
Процесс формирования психолого-педагогических компетенций у педагогов образовательных организаций
}

\author{
Беспаленко Е.М. \\ Институт развития образования имени Н.Ф. Бунакова, \\ Россия, 394043, г. Воронеж, ул. Березовая роща, 54 \\ E-mail: Elena2003b@mail.ru
}

\begin{abstract}
Аннотация. При реализации профессиональной деятельности педагога важной и необходимой является психолого-педагогическая компетенция, вопрос формирования которой остается не вполне изученным. В связи с этим автором предпринята попытка дать научное обоснование процесса формирования психолого-педагогических компетенций у педагогов образовательных организаций во время прохождения курсов повышения квалификации. В исследовании приняли участие 125 педагогов образовательных организаций Воронежа и области, обучающихся по дополнительным образовательным программам. Результаты исследования показали, что использованный комплекс специальных психологических методик, направленных на изменение психолого-педагогических знаний у педагогов является эффективным для формирования психолого-педагогических компетенций в том случае, если проблемные курсы повышения квалификации будут увеличены до 108-144 часов.
\end{abstract}

Ключевые слова: профессиональные качества, аутопсихологическая компетентность, самовосприятие, самооценка, эмоциональный статус, обучающиеся.

Для цитирования: Беспаленко Е.М. 2020. Проблемы формирования психолого-педагогических компетенций у педагогов образовательных организаций. Вопросы журналистики, педагогики, языкознания, 39 (2): 188-196. DOI 10.18413/2712-7451-2020-39-2-188-196

\section{Problems of formation of psychological and pedagogical competencies at teachers of educational organizations}

\author{
Elena M. Bespalenko \\ State budgetary institution of additional professional education \\ of the Voronezh region N.F. Bunakova, \\ 54 Berezovayaroshha St, Voronezh, 394043, Russia \\ E-mail: Elena2003b@mail.ru
}

\begin{abstract}
When implementing the professional activity of a teacher, psychological and pedagogical competence is important and necessary, since cases of deviations among children and adolescents have become more frequent, leading to fatal outcomes. However, the issue of formation of such competencies among teachers in the process of professional development remains not fully studied at the present time. In this regard, the author attempts to provide a scientific justification for the process of forming psychological and pedagogical competencies of teachers of educational organizations during the course of advanced training. The study was attended by 125 teachers of educational organizations in Voronezh and the region, who are trained in additional educational programs. A comparative analysis of the results of control and measurement materials in comparison with measurement and evaluation tools is given. There are significant differences in the formation of psychological and pedagogical competencies between the initial monitoring cross-section and after the completion of advanced training courses. The author draws attention to the development of autopsychological competence as the basis for the formation of
\end{abstract}


psychological and pedagogical competence. The results showed that the used complex of special psychological techniques aimed at changing psychological and pedagogical knowledge among teachers is an effective for the formation of psycho-pedagogical competences in that case, if the problematic courses will be increased to $108-144$ hours.

Keywords: professional quality, autopsychological competence, self-perception, self-esteem, emotional status, students.

For citation: Bespalenko E M. Problems of formation of psychological and pedagogical competencies at teachers of educational organizations. Issues in Journalism, Education, Linguistics, 39 (2): 188-196 (in Russian). DOI 10.18413/2712-7451-2020-39-2-188-196

\section{Введение}

С введением Федеральных государственных образовательных стандартов (ФГОС) поменялось отношение к образовательной системе. Образование в школе не должно быть просто трансляцией чужого опыта; оно не дается, а приобретается обучающимися через умственные усилия и предлагает пути для их саморазвития и самообучения. Задача педагога состоит в содействии формированию индивидуальных траекторий с учетом возможностей каждого конкретного школьника и оказанию педагогической и психологической помощи в его самореализации и развитии. Подача знаний по предмету и психологопедагогическое сопровождение в рамках реализации ФГОС - непременное условие для подготовки школьников к жизни с социально-ориентированным взглядом на мир в его единстве и разнообразии. В этом случае нельзя недооценить роль эмоциональноценностного компонента в системе образования, который относится к психологопедагогической компетенции педагога. Учебно-воспитательный процесс начинается с урока, уроком он и заканчивается. В связи с этим осуществлять обучение необходимо, ориентируясь на личностное развитие обучающихся, учет их особенностей и всестороннее раскрытие их интеллектуального и личностного потенциала.

Проведенный анализ научных работ за последние годы показал, что в них раскрыты важные аспекты повышения квалификации педагогов образовательных организаций. Усилия многих исследователей направлены на создание системы профессионального развития педагога, формирование его творческого и критического стилей мышления.

Проблема формирования профессиональных качеств педагога в системе повышения квалификации выступает предметом специального исследования А.С. Фетисова [2019]. Ученый исследовал влияние профессиональных качеств педагога на обучающихся в контексте здоровьесберегающей образовательной среды.

Таким образом, повышение квалификации педагогов - это целенаправленный процесс, ориентированный на постоянное совершенствование профессионализма, развитие педагогического мастерства и формирование новых компетенций.

При реализации профессиональной деятельности важной и необходимой является психолого-педагогическая компетенция, т.к. участились случаи девиаций среди детей и подростков, приводящие к фатальным исходам. За последний календарный год зафиксированы несколько случаев делинквентного поведения среди обучающихся, авитальной активностью, выраженным суицидальным поведением, закончившиеся летальным исходом. Тем не менее, в настоящее время остается не вполне изученным вопрос формирования психолого-педагогических компетенций у педагогов в процессе повышения квалификации. Повышение квалификации как механизм реагирования на дефициты в знаниях и профессиональных затруднениях работает достаточно эффективно, т.к. реализация дополнительных образовательных программ основана на принципах опережающего и регулирующего характера содержания обучения. В тоже время совершенствованию личности учителя как процессу упорядоченной деятельности по формированию психологопедагогических компетенций уделяется недостаточно внимания. 


\section{Степень научной разработанности проблемы}

Проблема формирования психолого-педагогических компетенций у педагогов образовательных организаций исследована учеными И.Б. Выпряжкиной [2004], И.А. Зимней [2004], С.Б. Серебряковой [2006], Н.Ф. Логиновой [2019] и др. Рассмотрение проблем психолого-педагогической компетентности педагогов образовательных организаций как части профессиональной компетентности рассмотрены в научных трудах многих ученых [Gopinathan et al., 2008; Беспаленко, 2015; Matos, Mendes, 2015; Yildiz, 2015; Лукьянова, 2017; Rakap et al., 2017: Ибрагимова, 2018; Адольф, Ильина, 2019].

Психолого-педагогическая компетентность педагога, по определению М.И. Лукьяновой [2017], - это совокупность определенных качеств личности, характеризующихся высоким уровнем профессиональной подготовленности к эффективному взаимодействию с обучающимися в образовательном процессе. Вопросы, связанные с учетом возрастныхособенностей обучающихся при планировании и проведении образовательной деятельности, актуализированы в работах А.А. Вербицкого [2016], Rakap S., Cig O., Parlak-Rakap A., [2017]; А.С. Фетисова [2019] и других ученых. Упомянутые авторы обращают внимание на недостаточный уровень психолого-педагогических компетенций у педагогов и необходимость усилить работу в этом направлении.

О том, каким требованиям должен отвечать профессиональный уровень педагога при поступлении на работу в школу, отражено в работе Matos S.N., Mendes E.G. [2015]. Авторы обращают внимание на уровень психологических знаний учителя, которые являются основой для создания индивидуальной траектории обучения и развития школьников.

Учеными QiJ., WangL., На A. [2017] поднимается вопрос об инклюзивном образовании, в том числе обучении детей с ограниченными возможностями здоровья на уроках физической культуры в Гонконге. Авторы отмечают, что учителя выражают обеспокоенность по поводу учебных и психологических барьеров для включения учащихся с ограниченными возможностями в общие программы. Но большую проблему создают недостаточные психологические компетенции педагогов, неготовность к инклюзивному образованию.

Преемственность между дошкольным и школьным образованием и компетентностные характеристики педагогов стали предметом рассуждений ученых Akdap Z., Haser 3. [2017] о важности раннего воспитания детей в дошкольной образовательной организации, где закладываются основные психические свойства личности, и о том, какие психологопедагогические знания должны иметь педагоги.

Рассмотренные многочисленные психолого-педагогические научные изыскания создали теоретическую и практическую предпосылки для осмысления проблемы формирования психолого-педагогической компетенции педагогов образовательных организаций на курсах повышения квалификации. Таким образом определилась цель исследования - поиск и научное обоснование процесса формирования психолого-педагогических компетенций у педагогов образовательных организаций во время прохождения курсов повышения квалификации.

Задачи исследования:

- разработка дополнительных образовательных программ курсов повышения квалификации, формирующих психолого-педагогическую компетенцию;

- подготовка образовательных кейсов-заданий по психологическим проблемам;

- включение в модульные программы проблемных педагогических ситуаций, проблемных психологических задач и проблемных психологических вопросов.

Гипотеза исследования: формирование психолого-педагогических компетенций педагогов образовательных организаций связано с актуализацией мотивационной, когнитивной, ценностно-смысловой, социально-коммуникативной и рефлексивно-регулятивной составляющих профессиональной деятельности и может быть обеспечена совокупностью психолого-педагогических условий и непрерывностью образования. 


\section{Объекты и методы исследования}

Методы исследования: измерительно-оценочные средства (ИОС), позволяющие выявить профессиональные затруднения педагогов; контрольно-измерительные материалы (КИМ), позволяющие определить сформированность психолого-педагогических компетенций. Исследование проходило в 2018-2019 годах. В исследовании приняли участие 125 педагогов образовательных организаций Воронежа и области, обучающихся по дополнительным образовательным программам «Профилактика девиантного поведения несовершеннолетних», «Профилактика суицидальных рисков в образовательных организациях», «Профилактика аддиктивного поведения несовершеннолетних».

К каждой модульной программе разработан учебно-методический комплекс, включающий тестовые задания, проблемные ситуации, проблемные задачи, проблемные вопросы.

\section{Результаты исследования}

Измерительно-оценочные средства позволили выявить профессиональные затруднения по следующим профессиональным компетенциям (ПК), общепрофессиональным компетенциям (ОПК) и общекультурным компетенциям (ОК):

- ОПК-2 - способность осуществлять обучение, воспитание и развитие с учетом социальных, возрастных других особенностей обучающихся;

- ОПК-3 - готовность к психолого-педагогическому сопровождению учебновоспитательного процесса;

- ПК-7 - совершенствование способности организовывать сотрудничество обучающихся, поддерживать активность и инициативность, самостоятельность обучающихся, развивать их творческие способности;

- ОК-9 - способность использовать приемы первой помощи, методы защиты в условиях чрезвычайных ситуаций.

Результаты изучения аутопсихологической компетентности педагогов методами ИОС и КИМ отражены в таблице.

Аутопсихологическаякомпетенцияпедагогов

Autopsychological competence of teachers

\begin{tabular}{|c|c|c|c|}
\hline & \multirow{2}{*}{ Свойства личности } & \multicolumn{2}{|c|}{ Диагностика } \\
\hline & & Первичная & Заключительная \\
\hline \multirow{4}{*}{$\begin{array}{l}\text { Самовосприятие } \\
\text { и самооценка }\end{array}$} & завышенная самооценка & $4 \%$ & $4 \%$ \\
\hline & высокая (нормальная) самооценка & $65 \%$ & $67 \%$ \\
\hline & заниженная самооценка & $28 \%$ & $27 \%$ \\
\hline & низкая самооценка (самоотрицание) & $3 \%$ & $2 \%$ \\
\hline \multirow{3}{*}{$\begin{array}{l}\text { Трансактный анализ } \\
\text { общения в образов- } \\
\text { тельных организа- } \\
\text { циях }\end{array}$} & демократичный стиль & $43 \%$ & $48 \%$ \\
\hline & либеральный стиль & $9 \%$ & $7 \%$ \\
\hline & авторитарный стиль & $48 \%$ & $45 \%$ \\
\hline \multirow{4}{*}{$\begin{array}{l}\text { Эмоциональный } \\
\text { статус }\end{array}$} & эмоциональная лабильность & $34 \%$ & $33 \%$ \\
\hline & агрессия (гипертрофированная) & $3 \%$ & $3 \%$ \\
\hline & защитная агрессия & $38 \%$ & $39 \%$ \\
\hline & $\begin{array}{l}\text { агрессия не выражена или не } \\
\text { диагностирована }\end{array}$ & $25 \%$ & $25 \%$ \\
\hline
\end{tabular}


Аутопсихологическая компетентность является одним из главных психологических условий развития личностного потенциала педагогов и предполагает осознание собственных индивидуально-личностных особенностей, выбор способов деятельности на основе знания самого себя. Высокий уровень аутопсихологической компетентности дает возможность эффективного саморазвития на основе управления внутренним ресурсом и способствует формированию психолого-педагогической компетенции.

Анализ полученных результатов показал, что большинство педагогов при первичной и заключительной диагностике концентрируются на своих переживаниях и проблемах. При интерпретации результатов у четверти педагогов вообще не удалось диагностировать некоторые свойства личности. Их аутопсихологическая компетентность возможно на высоком уровне, а возможно на низком.

Примерно у 43-48 \% педагогов выявлен демократичный стиль общения с обучающимися, т.е. им близки интересы и проблемы школьников, в работе преобладает гуманистическая направленность.

Эмоциональный статус не у всех педагогов благоприятен. Эмоциональная лабильность не создает атмосферу для плодотворной работы и не сохраняет психическое здоровье всех членов образовательного процесса. В исследуемом случае эмоциональная лабильность наблюдается у трети испытуемых. Отмечено, что после окончания курсов повышения квалификации эмоциональная лабильность у педагогов снизилась на 1 \%, что является хорошим показателем, учитывая тот факт, что курсы краткосрочные (от 48 до 54 часов).

Самые хорошие показатели по шкале «самовосприятие и самооценка». Адекватная самооценка, позитивное самовосприятие присуще 65 \% испытуемых на начальной диагностике и $67 \%$ на завершающем этапе. Можно предположить, и многие авторы [Адольф В.А., Ильина Н.Ф. 2019; Е.М. Беспаленко 2015; А.С. Фетисов, 2019] это подтверждают, что такие педагоги заинтересованы в личностном развитии школьников.

Завышенную самооценку имеют 4 \% респондентов. Это неблагоприятная ситуация, так как она опасна для этих педагогов риском возникновения фрустрации. Низкая самооценка у 3 \% на начальном этапе диагностики и у $2 \%$ на завершающем этапе. Это ожидаемо, но, с другой стороны, низкая самооценка - это группа риска по возникновению у педагогов психоэмоциональных нарушений и невротических расстройств [Беспаленко, 2015].

Практические занятия в рамках реализации модульных программ позволили в значительной степени повысить уровень психолого-педагогических знаний педагогов. Приведем наиболее эффективные методы формирования психолого-педагогических компетенций у педагогов образовательных организаций: практические занятия по темам «Метафора моей работы», «Идеи психолого-педагогического сопровождения школьников»; кейсзадания «Передайте смысл пословицы», «Найдите причину психологического неблагополучия ребенка», «Социальная коммуникация», «Индивидуально-психологическая характеристика, мысли и чувства картины "Опять двойка" художника Фёдора Решетникова» и другие.

Приносят хорошие результаты такие активные методы формирования психологопедагогических компетенций, как деловые игры «Родительское собрание "Профилактика авитальной активности обучающихся"», «Педагогические советы "Рисунок песком", "Проблемное поле - отсутствие мотивации учения"» и другие; тренинги «Мотивация избегания неудачи: как корректировать», «Сущность личностно-ориентированного подхода в образовании», «Коммуникативная девиация: проблемы и решение проблем» и др.; Психологические упражнения «Кто есть кто?», «Перевоплощение», «Театральный сюжет» и др.

Также эффективными являются педагогические супервизии.

Проведенные контрольно-измерительные материалы при завершении курсов повышения квалификации показывают, что методы, используемые для формирования пси- 
холого-педагогической компетенции эффективны, но количество часов, выделяемое на проведение проблемных курсов, ограничивается часами от восемнадцати до тридцати шести. Учитывая остроту проблемы - это недостаточно для овладения педагогами перечисленными выше компетенциями.

Достоверность результатов исследования обеспечивается целостной методологической базой исследования, обоснованностью и адекватностью используемых методов. Процедура психологического исследования и формирования психолого-педагогических компетенций у педагогов образовательных организаций опирается на данные современной психолого-педагогической науки, системный подход к формированию предмета исследования, на концептуальный и практический уровень. Исследование отличается репрезентативностью полученных результатов формирования психолого-педагогической компетенции педагогов образовательных организаций.

\section{Заключение}

Значимость психолого-педагогических компетенций педагогов образовательных организаций подтверждается их включенностью в оценку профессиональной компетентности педагога при проведении аттестации и является частью системы роста педагогического мастерства. Для обеспечения процесса формирования психолого-педагогической компетенции у педагогов образовательных организаций необходимо решение следующих задач:

-изучить профессиональные затруднения не только в предметной области, а по четырем видам компетенций (психолого-педагогической, коммуникативной, предметной и методической);

-расширить спектр стажировок, включая психолого-педагогическую направленность;

-создать тьютерскую помощь для педагогов;

-ввести в практику педагогическую супервизию;

-обеспечить психолого-педагогическое сопровождение педагогов;

-расширить тематику круглых столов, вебинаров, семинаров, т.е. выделить в отдельную проблему формирование психолого-педагогической компетенции и рассматривать ее с ведущими психологами, суицидологами, специалистами в области конфликтологии, девиантологии, социальными психологами.

Формирование психолого-педагогической компетенции является необходимой составляющей профессиональной компетентности педагога, обеспечивающей решение профессиональных задач конструктивного взаимодействия и общения с участниками образовательного процесса на основе учета психофизических, возрастных и индивидуальных особенностей обучающихся.

Система формирования психолого-педагогических компетенций у слушателей подтверждается положениями системного, личностного, деятельностного, контекстного и компетентностного подходов с целью более точного раскрытия процесса интегрирования профессиональных и личностных качеств педагогов, закономерностями, присущими процессу формирования профессиональных их качеств в личностно-ориентированном образовании.

Формирование психолого-педагогических компетенций у педагогов можно рассматривать как одну из сложных динамических систем, полноценное функционирование которой возможно лишь при наличии обратной связи между средой и системой.

Формирование психолого-педагогических компетенций у педагогов на курсах повышения квалификации осуществляется в контексте их деятельности, направленной от учебной к профессиональной деятельности [Вербицкий, 2016]. Для достижения успешного процесса формирования психолого-педагогических компетенций у педагогов необходимо 
разрабатывать и реализовывать дополнительные образовательные программы по тематикам, касающимся отклоняющегося поведения обучающихся, медицинского просвещения, формирования культуры нравственного, психического, психологического здоровья. Решение данной проблемы возможно, если курсы повышения квалификации будут непрерывными, количество часов на слушателя возрастет до 108-144 часов, и будет обеспечено психологопедагогическое сопровождение профессионального мастерства педагогов.

\section{Список литературы}

1. Адольф В.А., Ильина Н.Ф. 2019. Инновационная деятельность в образовании: вопросы теории и практики. Красноярск, $180 \mathrm{c}$.

2. Беспаленко Е.М. 2015. Особенности развития и течения невротических расстройств у педагогов с нервно-психической неустойчивостью. Молодой ученый, 7 (87): 266-269.

3. Вербицкий А.А. 2016. «Цифровое поколение»: проблемы образования. Профессиональное образование. Столица, 7: 10-13.

4. Выпряжкина И.Б. 2004. Психолого-педагогическая компетентность учителей гимназических классов: динамика, развитие, оценка при аттестации. Дис... канд. психол. наук. Москва, $186 \mathrm{c}$.

5. Зимняя И.А. 2004. Ключевые компетентности как результативно-целевая основа компетентностного подхода в образовании. М., Исследовательский центр проблем качества подготовки специалистов, $42 \mathrm{c.}$

6. Ибрагимова Ш.Х. 2018. Профессиональная компетентность учителя иностранного языка. Молодой ученый, 22 (208): 315-316.

7. Логинова Н.Ф. 2019. Становление психолого-педагогической компетентности молодого педагога с использованием потенциала региональной системы образования. Дисс...канд. пед. наук. Красноярск, 257 с.

8. Лукьянова М.И. 2017. Теоретический анализ феномена готовности учителя к реализации личностно-ориентированного подхода в понятийном поле категории «психологопедагогическая компетентность». Научноеобозрение. Педагогическиенауки, 4: 110-123.

9. Серебрякова С.Б. 2006. Формирование психолого-педагогической компетентности педагога дополнительного образования. Дис. ... докт. пед. наук. Москва, 503 с.

10. Фетисов А.С. 2019. Системообразующая доминанта формирования профессиональных качеств педагога в системе повышения квалификации. Воронеж, Научная книга, $241 \mathrm{c}$.

11. Akdap Z., Haser 3. 2017. Beginning early childhood education teachers' struggle with inclusion in Turkey. Asia Pacific Journal of Education, 17: 1-13.

12. Fransson G. 2012. Head Teachers on Evaluating Newly Qualified Teachers' Competencies: What to Focusonand How. In: Teachers' Life-cycle from Initial Teacher Education to Experienced Professional. Eds. I. Юogla, L. Rutka, Brussels, Belgium, ATEE: 79-90.

13. Gopinathan S., Tan S., Fang Y., Ponnusamy L.D., Ramos C., Chao E. 2008. Transforming teacher education: Redefining professionals for 21 st century schools. Singapore, National Institute of Education, 10: 2012.

14. Matos S.N., Mendes E.G. 2015. Teacher demands resulting from school inclusion. Revista Brasileira de Educacao Especial, 21 (1): 9-22.

15. Islamova Z. I., Semenova G. E. 2014. Valuetargeted organizational and substantive base of SCO under the direction of «Pedagogy». Ufa, BSPU Publisher, $253 \mathrm{p}$.

16. Korthagen F.J., Lughran J., Russell T. 2006. Developing fundamental principles for teacher education programs and practices. Teaching and Teacher Education, 22 (8): 1020-1041.

17. Qi J., Wang L., Ha A. 2017. Perceptions of Hong Kong physical education teachers on the inclusion of students with disabilities. Asia Pacific Journal of Education, 37 (1): 86-102.

18. Rakap S., Cig O., Parlak-Rakap A. 2017. Preparing preschool teacher candidates for inclusion: impact of two special education courses on their perspectives. Journal of Research in Special Educational Needs, 17: 98-109.

19. Robert I.V. 2010. Modern information technologies in education. Moscow, Academia. 140 p. 
20. Yildiz N.G. 2015. Teacher and student behaviors in inclusive classrooms. Kuramve Uygulamada Egitim Bilimleri, 15: 177-184.

21. Zeer E.F. 2014. Social-professional mobility of learning youth as a factor of preparation for dynamic professional future. Education and science, 8: 33-48.

\section{References}

1. Adol'f V.A., Il'ina N.F. 2019. Innovatsionnaya deyatel'nost' v obrazovanii: voprosy teorii $\mathrm{i}$ praktiki [Innovative activity in education: issues of theory and practice]. Krasnoyarsk, $180 \mathrm{p}$.

2. Bespalenko E.M. 2015. Osobennosti razvitiya i techeniya nevroticheskikh rasstroystv u pedagogov s nervno-psikhicheskoy neustoychivost'yu [Features of development and course of neurotic disorders in teachers with neuropsychiatric instability]. Molodoy uchenyy, 7 (87): 266-269.

3. Verbitskiy A.A. 2016. «Tsifrovoe pokolenie»: problemy obrazovaniya [The "digital generation": challenges of education]. Professional'noe obrazovanie. Stolitsa, 7: 10-13.

4. Vypryazhkina I.B. 2004. Psikhologo-pedagogicheskaya kompetentnost' uchiteley gimnazicheskikh klassov: dinamika, razvitie, otsenka pri attestatsii [Psychological and pedagogical competence of high school teachers: dynamics, development, assessment during certification]. Dis... cand. psikhol. sciences. Moskva, $186 \mathrm{p}$.

5. Zimnyaya I.A. 2004. Klyuchevye kompetentnosti kak rezul'tativno-tselevayaosnova kompetentnostnogo podkhoda $\mathrm{v}$ obrazovanii [Key competencies as a result-oriented basis of the competence approach in education]. M., Publ. Issledovatel'skiy tsentr problem kachestva podgotovki spetsialistov, $42 \mathrm{p}$.

6. Ibragimova Sh. Kh. 2018. Professional'naya kompetentnost' uchitelya inostrannogo yazyka [Professional competence of a foreign language teacher]. Molodoy uchenyy, 22 (208): 315-316.

7. Loginova N.F. 2019. Stanovlenie psikhologo-pedagogicheskoy kompetentnosti molodogo pedagoga $\mathrm{s}$ ispol'zovaniem potentsiala regional'noy sistemy obrazovaniya [Formation of psychological and pedagogical competence of a young teacher using the potential of the regional education system]. Diss...cand. ped. sciences. Krasnoyarsk, 257 p.

8. Luk'yanova M.I. 2017. Theoretical analysis of the phenomenon of readiness of the teacher to the realization of personality oriented approach in the conceptual category field «Professional pedagogical competence». Scientific review. Pedagogical science, 4: 110-123 (in Russian).

9. Serebryakova S.B. 2006. Formirovanie psikhologo-pedagogicheskoy kompetentnosti pedagoga dopolnitel'nogo obrazovaniya [Formation of psychological and pedagogical competence of a teacher of additional education]. Dis. ... dokt. ped. sciences. Moskva, 503p.

10. Fetisov A.S. 2019. Sistemoobrazuyushchaya dominanta formirovaniya professional'nykh kachestv pedagoga $\mathrm{v}$ sisteme povysheniya kvalifikatsii [System-forming dominant of formation of professional qualities of the teacher in the system of professional development]. Voronezh, Publ. Nauchnaya kniga, $241 \mathrm{p}$.

11. Akdap Z., Haser 3. 2017. Beginning early childhood education teachers' struggle with inclusion in Turkey. Asia Pacific Journal of Education, 17: 11-13.

12. Fransson G. 2012. Head Teachers on Evaluating Newly Qualified Teachers' Competencies: What to Focusonand How. In: Teachers' Life -cycle from Initial Teacher Education to Experienced Professional. Eds. I.Юogla, L. Rutka, Brussels, Belgium, ATEE: 79-90.

13. Gopinathan S., Tan S., Fang Y., Ponnusamy L.D., Ramos C., Chao E. 2008. Transforming teacher education: Redefining professionals for 21 st century schools. Singapore, National Institute of Education, 10: $2012 \mathrm{p}$.

14. Matos S.N., Mendes E.G. 2015. Teacher demands resulting from school inclusion. Revista Brasileira de Educacao Especial, 21 (1): 9-22.

15. Islamova Z. I., Semenova G. E. 2014. Valuetargeted organizational and substantive base of SCO under the direction of «Pedagogy». Ufa, BSPU Publisher, $253 \mathrm{p}$.

16. Korthagen F.J., Lughran J., Russell T. 2006. Developing fundamental principles for teacher education programs and practices. Teaching and Teacher Education, 22 (8): 1020-1041. 
17. Qi J., Wang L., Ha A. 2017. Perceptions of Hong Kong physical education teachers on the inclusion of students with disabilities. Asia Pacific Journal of Education, 37 (1): 86-102.

18. Rakap S., Cig O., Parlak-Rakap A. 2017. Preparing preschool teacher candidates for inclusion: impact of two special education courses on their perspectives. Journal of Research in Special Educational Needs, 17: 98-109.

19. Robert I. V. 2010. Modern information technologies in education. Moscow, Academia. 140 p.

20. Yildiz N.G. 2015. Teacher and student behaviors in inclusive classrooms. Kuramve Uygulamada Egitim Bilimleri, 15: 177-184.

21. Zeer E.F. 2014. Social-professional mobility of learning youth as a factor of preparation for dynamic professional future. Education and science, 8: 33-48.

\section{ИНФОРМАЦИЯ ОБ АВТОРЕ}

Беспаленко Елена Михайловна, кандидат педагогических наук, доцент, доцент кафедры физической культуры, основ безопасности жизнедеятельности и воспитательных технологий Института развития образования имени Н.Ф. Бунакова, г. Воронеж, Россия

\section{INFORMATION ABOUT THE AUTHOR}

Elena M. Bespalenko, candidate of pedagogics. associate Professor, associate Professor of the Department of physical culture, fundamentals of life safety and educational technologies, Bunakov Institute for educational development, Voronezh, Russia 